\title{
Swab Me, I am Infected!
}

Aya M. Mahros, Mohamed H Emara, Mohammed H. Ahmed, Mohamed Said Radwan, Hassan E. Elbatee

Department of Hepatology, Gastroenterology and Infectious Diseases, Faculty of Medicine, Kafrelshiekh University, Kafrelshiekh, Egypt

Corresponding Author Aya M. Mahros

Mobile:

00201119088009

E mail: yoye_85@hotmail.com

Key words: COVID-19; Cough; Swabbing
In the late December 2019 an outbreak of a novel coronavirus termed as SARSCoV-2 has emerged in Wuhan city, China then spread worldwide to cause serious life threatening pandemic that seriously affect the economics and daily life. The classical picture of COVID-19 is described as fever, cough and dyspnea. However, different atypical presentations have been described in the literature. We confronted by a patient 49 years old without respiratory manifestation who sought medical advice for swabbing for COVID-19, with refusal from the local governmental center for swabbing, two days later, the patient become dyspneic, desaturated with positive COVID-19 swab. We recommend that care givers should not wait the full typical respiratory manifestations of COVID-19.We also realize that there is a big shortage in swabbing and examination tools especially in the developing countries like ours, however, caregivers in swabbing center should have a high index of suspicion with patients who have persistent symptoms.

\section{INTRODUCTION}

In the late December 2019 an outbreak of a novel coronavirus termed as SARS- CoV-2 has emerged in Wuhan city, China [1] with many severe cases of pneumonia and then the disease spread worldwide to be recognized by WHO as a global pandemic in February, 2020 [2]. The clinical manifestations of this virus is termed COVID-19; it is associated with global life threatening health problem that is associated with global economy and daily life impairments. By the end of April 2020, more than 200,000 deaths and more than 3 million confirmed cases were reported.

The disease invaded our Middle East community and national emergency was announced nearly in all countries of the region facing this widely spreading infection. Different visual triage checklists were developed in each country to be applied by the national health care systems. These forms were available both in Arabic e.g. the Egyptian case definition sheet
(Figure 1) and also in English e.g. the Saudi visual triage checklist (Figure 2) to help both the health care givers (local with native Arabic and international with English languages) and patients as well.

During this pandemic, the classical picture of COVID-19 is described as fever, cough and dyspnea $[3,4]$. However, different atypical presentations have been described in the literature. Some authors described that, cases of COVID-19 may present as deterioration of the previously stable conditions with sudden hypoxemia in stable Alzheimer disease [5], syncope [6], sudden impairments of taste and smell sensations [7], lone GIT manifestations including anorexia, nausea, vomiting and diarrhea [8], although some patients were accidentally discovered upon on chest imaging [9]. 


\section{CASE DESCRIPTION}

We confronted by a 49 years male patient. He gave history started 10 days back with generalized fatigue, chills and bone pains, he claimed low grade fever, but he denied cough, dyspnea. He sought medical advice in a local governmental center for COVID-19 swabbing. Unfortunately, they refused to do the swab depending on the lack of the definition criteria described in the triage checklist (Figure 1 and 2). He was told that no history of exposure to a potential source of infection, no cough or dyspnea and the measured temperature is within normal. Two days later, the patient went gain to the same center due to persistent symptoms and was given the same advice. Three days later the patient noticed an increasing shortness of breath. At the triage area of another hospital the patient was not feverish nor coughing and hence was not shifted to the ER and was directed to the OPD. On examination the patient was mildly dyspneic, temperature $37.4 \mathrm{C}$. Bilateral medium sized wet crepitation were heard on chest auscultation. Chest $\mathrm{x}$ ray was done and showed bilateral diffuse lung opacities (Figure 3). The patient was admitted on isolation room and a swab for COVID-19 was obtained and the result was positive. Upon admission, he becomes more dyspneic, the patient was desaturated and was shifted to the ICU.

His investigations on admission included: Total leukocyte count $\left(7.4 \times 10^{3}\right)$, with relative lymphopenia $(14.5 \%)$, relative monocytosis (15.3\%), Hemoglobin $14.6 \mathrm{gm} \%$, platelets 176 $\times 10^{3}$, CRP 9.7, Ferritin90.2, D dimmer $0.1 \mathrm{mg} / \mathrm{L}$.

\section{DISCUSSION}

We intended to deliver multiple messages from this case. First, the absence of respiratory manifestations initially. Cough in particular is an annoying symptom not only for the patients but also for the contacts. In fact, different reports in the literature confirmed absence of cough as the presenting symptom of COVID-19 [5-9]. Consequently, we deliver the same massage to care givers that typical respiratory manifestations may not be present among cases with COVID19.
Second, swabbing: we realize that there is a big shortage in swabbing and examination tools especially in the developing countries like ours and also we noticed that even in the more developed and rich countries tools are not sufficient for the wide scale public examination. However, caregivers in swabbing centers should have a high index of suspicion with patients who have persistent symptoms. They should think out of the box. Following the visual triage implemented by local health authorities is very essential but this visual triage checklist was changing rapidly. For instance, some triage checklists were initially included flu, sore throat and runny nose that later omitted. In addition, the history of travel in the previous 14 days to an area of high transmission was changing very rapidly and in some countries, it was even changing daily. Furthermore, different countries affected had various hot spot districts within the same country (Figure 4).

Third, during an increased transmission rate within a locality with available testing facilities any person with changed medical condition and have an access to examination should be clinically evaluated and swabbed if possible.

Fourth, a message for patients rather than health caregivers. Unnoticed, unprotected contact with symptomatic or asymptomatic persons during the incubation period of the disease or exposure to potentially infected places e.g. markets, transportation means, within companies...etc., represent a real risk and hence whenever possible a policy of home stay and social distancing is very important.

Last, individuals are now minded with all aspects of COVID-19 infection and the different methods of protection. They should apply protective measures and insist on seeking the medical advice as soon as they develop new complains or experience persistence of symptoms

In conclusion, we recommend all health centers to swab whenever possible patients even in the absence of cough or other respiratory manifestations particularly when the local transmission is high. Waiting for full criteria of a visual triage may be a bomb that threatens the community. 


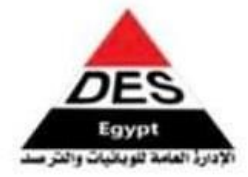

وزارة الصحة والسكان

قُطاع الطب الوقاني

الإدارة المركزية للثبون اللوقانية

الإدارة العامة للوبانيات و الترصد التراند

\section{تعريف موقت لحالة الاصابة بفيروس الكورونا المستجدة (COVID-19)}

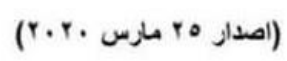

الحالة المشتبه

$$
\begin{aligned}
& \text { أ. أي شخص بعاني من أي من الأعر اض التنفسية الحادة مثل (كحة ، ضيق في التنفس) أو ارنفاع فى درجة }
\end{aligned}
$$

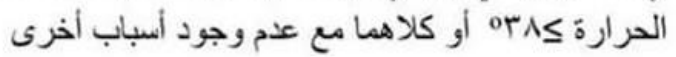

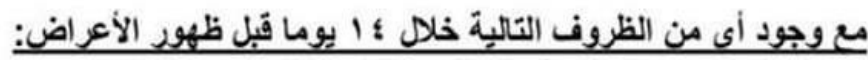

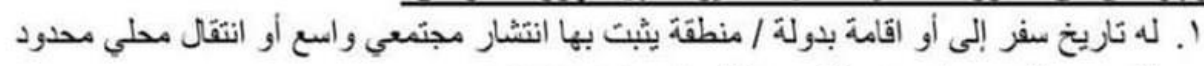

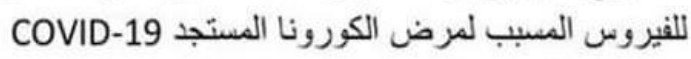

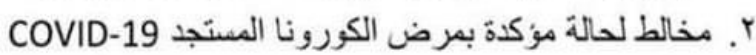

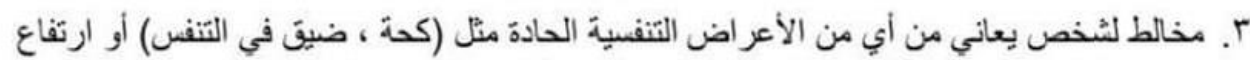

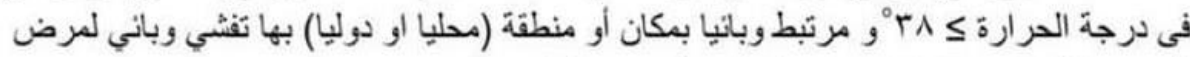

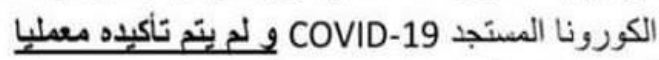

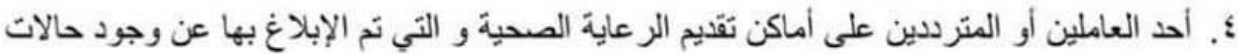

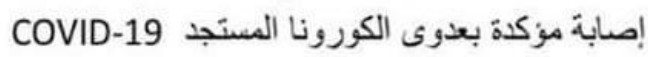

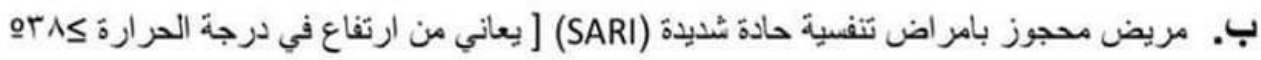

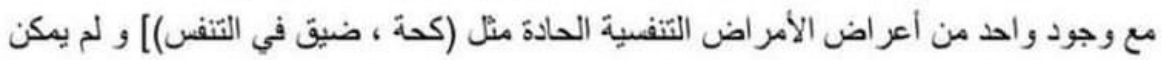

$$
\begin{aligned}
& \text { التعرف على المسبب للحالة المرضية له (مرفق توضيح بالفاكس المرسل لسيادتكم) }
\end{aligned}
$$

$$
\text { ج. أو أي شخص ينطبق عليه جمبع الخصانص الأكلينيكية التالية: }
$$

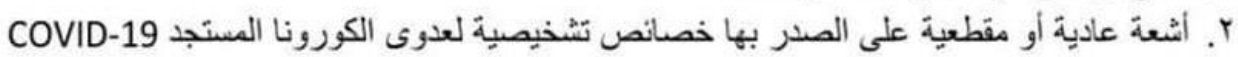

r. ب. عد طبيعي أو منخفض لكر ات الدم البيضاء) (Total leukocyte count) مع انخفاض كرات الدم

$$
\text { الليمفاوية (lymphocytopenia) }
$$

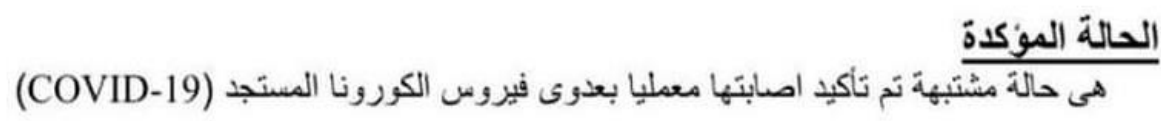

Figure 1: The Egyptian case definition checklist in Arabic early during the epidemic 


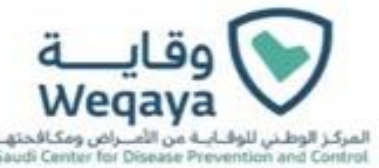

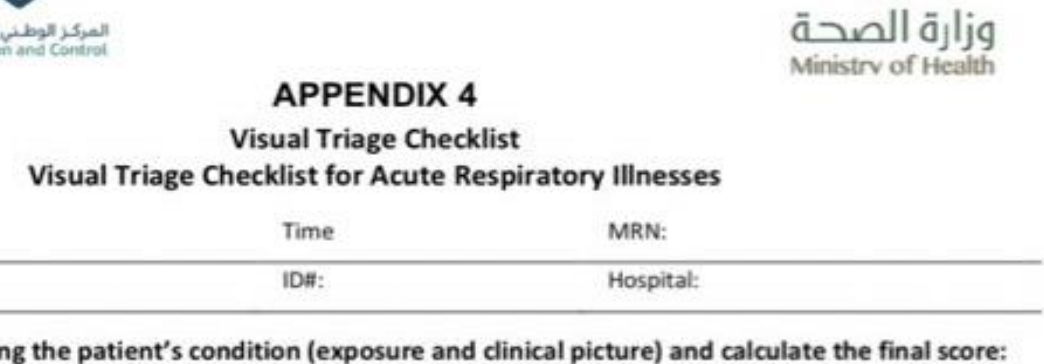

Visual Triage Checklist

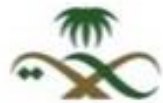

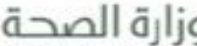

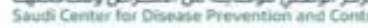

Circle the number reflecting the patient's condition (exposure and clinical picture) and calculate the final score:

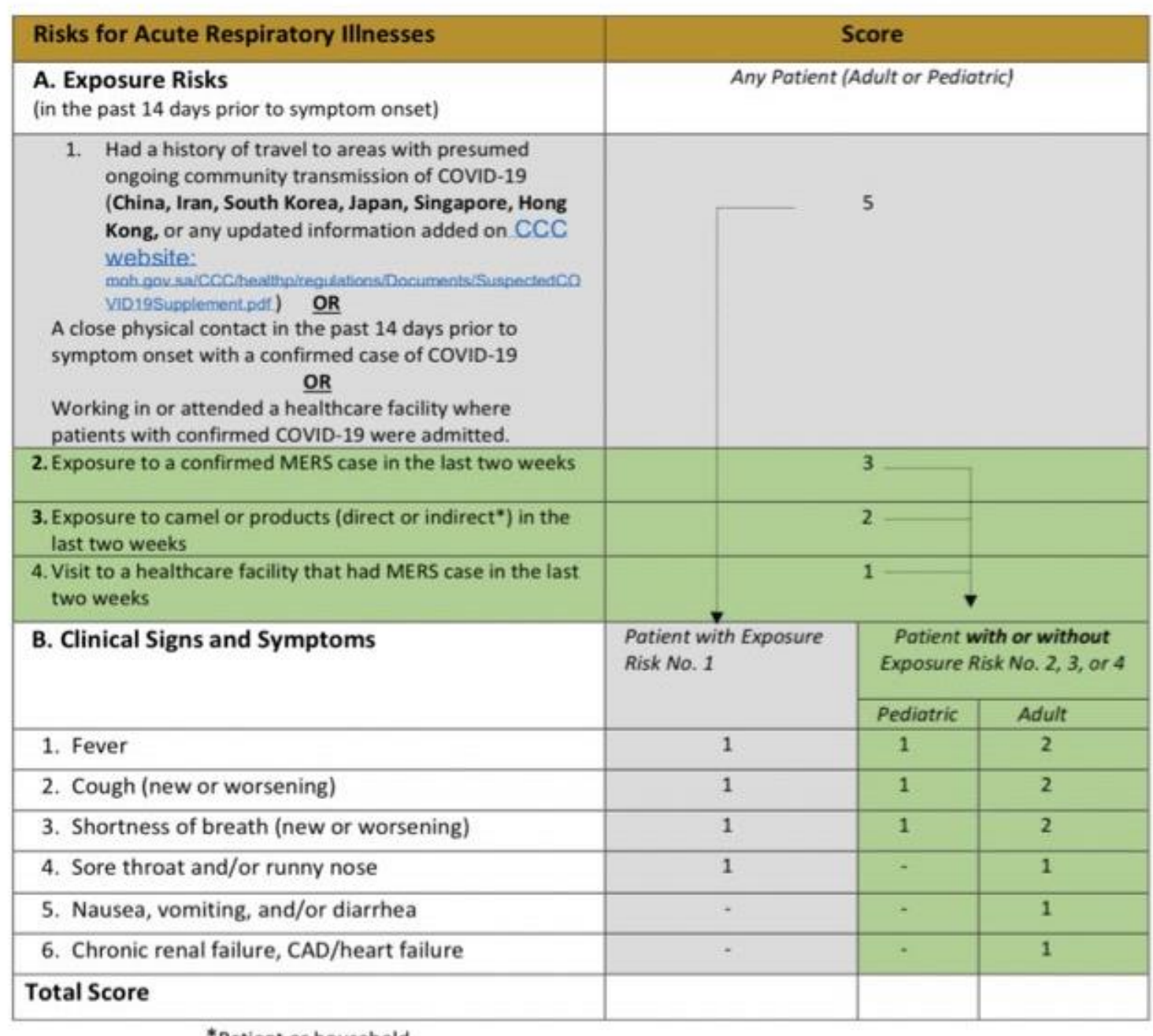

* Patient or household

\begin{abstract}
A score $\geq 4$, place patient in an isolation room and inform MD for assessment. MERS-CoV testing should be done only according to case definition.

A score $\geq 6$, place patient in an isolation room and inform MD for assessment. CoviD-19 testing should be done only according to case definition.
\end{abstract}

Staff name:

ID number:

Figure 2: The Saudi case definition checklist in English early during the epidemic 


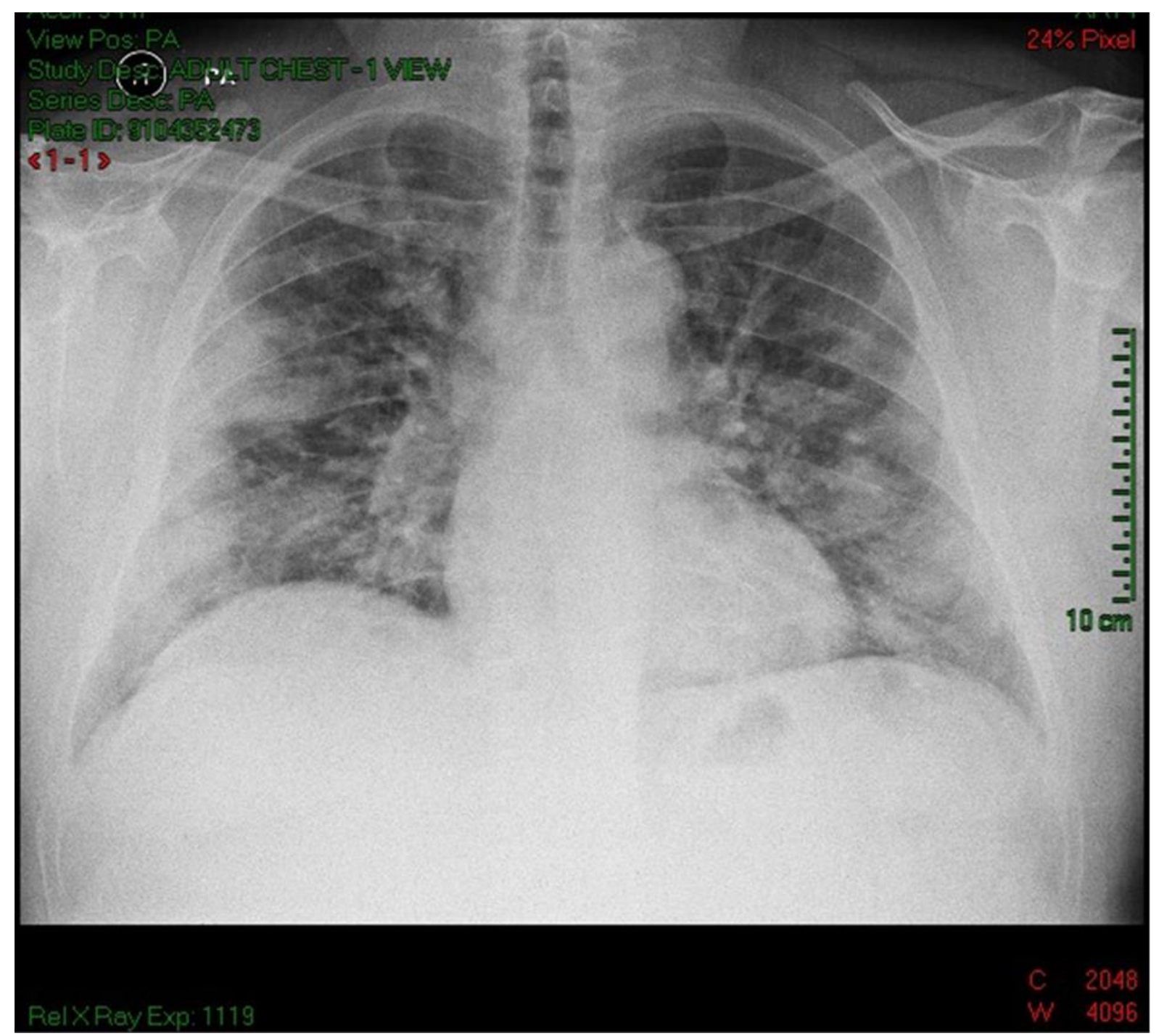

Figure 3: Chest X-ray of the chest on the day of admission showing bilateral consolidation opacities.

Mahros et al., Afro-Egypt J Infect Endem Dis 2021; 11(1):88-94

https://aeji.journals.ekb.eg/

http://mis.zu.edu.eg/ajied/home.aspx 


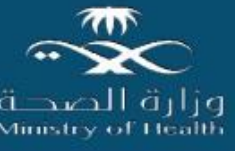

\section{Respiratory Triage Checklist}

Date:

Time

Name: Hospital:

Circle the number reflecting the patient's condition (exposure and clinical picture) and calculate the final score:

\begin{tabular}{|c|c|c|}
\hline Risks for Acute Respiratory Illnesses & \multicolumn{2}{|c|}{ Score } \\
\hline A. Exposure Risks & \multicolumn{2}{|c|}{$\begin{array}{l}\text { Any Patient (Adult or } \\
\text { Pediatric) }\end{array}$} \\
\hline $\begin{array}{l}\text { A history of travel abroad during the } 14 \text { days prior to symptom onset. } \\
\text { Visiting or being a resident of a high-risk area for COVID-19 in the } \\
\text { kingdom during the } 14 \text { days prior to symptom onset*. } \\
\text { A close physical contact with a confirmed case of COVID-19 or } \\
\text { MERS-CoV in the past } 14 \text { days. } \\
\text { An exposure to camel or camel's products (direct or indirect**) in } \\
\text { the past } 14 \text { days. } \\
\text { Working in a healthcare facility. }\end{array}$ & \multicolumn{2}{|c|}{3} \\
\hline B. Clinical Signs and Symptoms and Medical History & Pediatric & Adult \\
\hline 1. Fever or recent history of fever. & 1 & 2 \\
\hline 2. Cough (new or worsening). & 1 & 2 \\
\hline 3. Shortness of breath (new or worsening). & 1 & 2 \\
\hline 4. Nausea, vomiting, and/or diarrhea. & - & 1 \\
\hline $\begin{array}{l}\text { 5. Chronic renal failure, CAD/heart failure, Immunocompromised } \\
\text { patient. }\end{array}$ & - & 1 \\
\hline Total Score & & \\
\hline
\end{tabular}

* As determined and announced by the Ministry of Interior or Ministry of Health. Updated regularly on: www.covid19.cdc.gov.sa

** Patient or household

\section{A score $\geq 4$, ask the patient to perform hand hygiene, wear a surgical mask, direct the patient} through the respiratory pathway and inform MD for assessment. MRSE-CoV OR COVID-19 testing should be only done according to case definitions.

Staff name: Signature:

Figure 4: The modified Saudi case definition checklist in English later during the epidemic. Note that the list of countries with high transmission listed early in the epidemic was replaced later by history of travel abroad whatever the cautery was. Also, note that upper respiratory manifestations e.g. sore throat and runny nose were not included in the latest triage checklist. 
Ethics and Consent: This study was performed in accordance with the Declaration of Helsinki, Good Clinical Practice and applicable regulatory requirements. Written informed consent was taken from the patient.

\section{ACKNOWLEDGMENT}

The authors would thank all colleagues who helped to document this case

\section{Conflict of interest: None}

\section{REFERENCES}

1. Wu Y, Ho W, Huang Y, Jin DY, Li S, Liu SL et al. SARS-CoV-2 is an appropriate name for the new coronavirus. Lancet. 2020 Mar 21;395(10228):949-950.

2. Legido-Quigley H, Asgari N, Teo YY, Leung GM, Oshitani H, Fukuda K et al. Are highperforming health systems resilient against the COVID-19 epidemic? Lancet. 2020 Mar 14;395(10227):848-850.

3. Wang D, Hu B, Hu C, Zhu F, Liu X, Zhang J, et al. Clinical Characteristics of 138 Hospitalized Patients With 2019 Novel Coronavirus-Infected Pneumonia in Wuhan, China. JAMA. 2020 Mar 17;323(11):1061-1069.
4. Young BE, Ong SWX, Kalimuddin S, Low JG, Tan SY, Loh J, et al. Epidemiologic Features and Clinical Course of Patients Infected With SARS-CoV-2 in Singapore. JAMA. $2020 \mathrm{Apr}$ 21;323(15):1488-1494.

5. Isaia G, Marinello R, Tibaldi V, Tamone C, Bo M. Atypical Presentation of Covid-19 in an Older Adult With Severe Alzheimer Disease. Am J Geriatr Psychiatry. 2020 Jul;28(7):790-791

6. Singhania N, Bansal S, Singhania G. An Atypical Presentation of Novel Coronavirus Disease 2019 (COVID-19). Am J Med. 2020 Jul;133(7):e365-e366.

7. Xydakis MS, Dehgani-Mobaraki P, Holbrook EH, Geisthoff UW, Bauer C, Hautefort C,et al. Smell and taste dysfunction in patients with COVID-19. Lancet Infect Dis. 2020 Sep;20(9):1015-1016.

8. Tian Y, Rong L, Nian W, He Y. Review article: gastrointestinal features in COVID-19 and the possibility of faecal transmission. Aliment Pharmacol Ther. 2020 May;51(9):843-851.

9. Asadollahi-Amin A, Hasibi M, Ghadimi F, Rezaei H, SeyedAlinaghi S. Lung Involvement Found on Chest CT Scan in a Pre-Symptomatic Person with SARS-CoV-2 Infection: A Case Report. Trop Med Infect Dis. 2020 Apr 7;5(2):56. 